\title{
Three weeks with strangers: Photography and the production of social identity during the 1935 Board of Anthropological Research expedition to the Warburton Range, Western Australia
}

\author{
Pamela Faye McGrath \\ The Australian National University, Australian Institute of Aboriginal and Torres Strait Islanders Studies
}

\begin{abstract}
Using a range of archival and published sources including field notes, photographs and drawings, this paper investigates the social relationships formed between Ngaanyatjarra families and a small group of scientists in the presence of cameras during a 3-week ethnographic research expedition to the Warburton Range in 1935. The impression left by the ethno-historical record is that, despite disparate norms around looking behaviours, a degree of familiarity was quickly established that enabled intimate acts of filming and photography. And yet the inter-subjectivity that facilitated such photography was deliberately obscured when the images produced were subsequently disseminated to outside audiences, in effect reinstating social distance and turning Aboriginal familiars back into strangers. Recent reconsiderations of the figure of 'the stranger' (Simmel 1999; Marotta 2012) and an extensive literature on the relationship between anthropological knowledge and photography (Edwards 1992, 2001) help to unpack what this sociality reveals about belonging, identity and the representative reach of photographic mediums. A series of crayon drawings by the expedition's young Aboriginal guide points to the limits of the social categories assumed for Ngaanyatjarra people by these scientists. In their place is found complex contemporary Aboriginal identities that were simultaneously modern and traditional, embedded in evolving intergenerational social frameworks that have endured until today.
\end{abstract}

Keywords: Photography, identity, stranger sociality, Ngaanyatjarra, Aboriginal Australia

In the winter of 1935 a small team of scientists led by the anthropologist Norman Tindale made a 6-day journey by truck from the mining town of Laverton in Western Australia to Warupuyu, a small soak on Elder Creek in the Warburton Range. There they established a temporary camp from where, for the next 3 weeks, they conducted intensive ethnographic research among the local Aboriginal population. Located on the south eastern fringe of the Gibson Desert, hundreds of kilometres from the nearest town in an area of unreliable rainfall, this was a remote and potentially very productive field site. Historically Warupuyu had been a place where 
Aboriginal society had been able to thrive, and yet the people who lived there were strangers to science, imagined to be 'practically untouched by civilisation' (Mountford 1938: 111).

The expedition was one of number of such endeavours sponsored by the Board of Anthropological Research at the University of Adelaide during the 1930s and 1940s (Fig. 1). ${ }^{1}$ Tindale's party included E.O. Stocker (cinematographer), Charles Mountford (photographer and 'aboriginal art' expert), and C.J. Hackett (physiologist). The expedition team also included E. Gutteridge, a Laverton local engaged as a recording clerk and general assistant (Tindale 1936: 481). Given their diverse disciplines and knowledge-seeking intent, I refer to these men collectively as 'the scientists'.

Two Aboriginal guides were also members of the expedition party, engaged at Laverton on the recommendation of a local policeman. In his mid-twenties, Peter Pitawara was the older of the two. He was identified as coming from 'Kanba' [Kanpa],

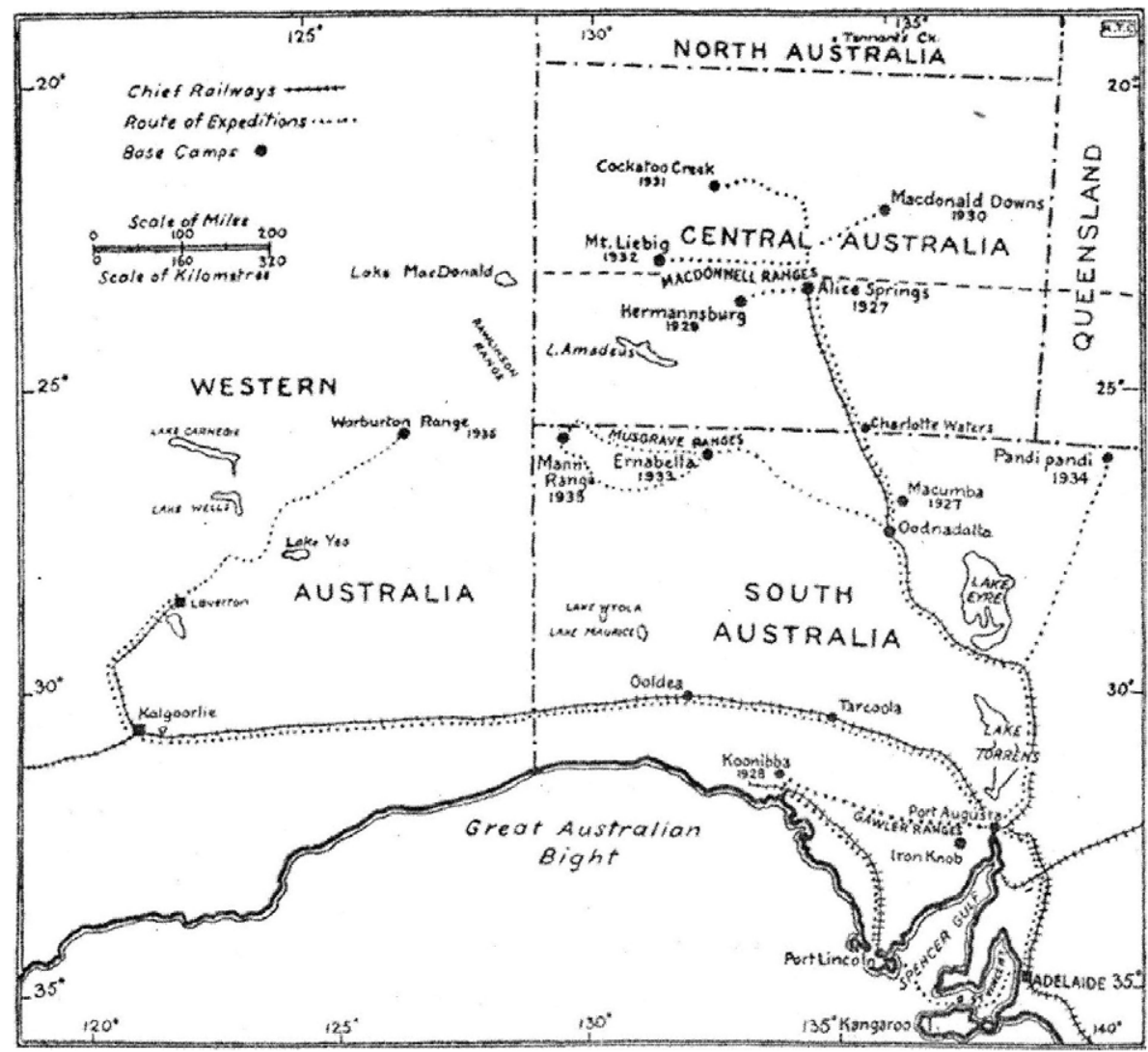

Figure 1 'Map showing routes taken by various expeditions organized by Board of Anthropological Studies, University of Adelaide' (Tindale 1936: 482). Courtesy of Oceania. 
located between Laverton and the Warburton Range with maternal links to the Warburton Range but, according to Tindale, the people of Warupuyu 'did not know [him]' (Tindale 1935a: 50). The younger guide was Nijau Jack, approximately 16 years of age. Nijau was from Tjilka:li [Tjirrkarli] near Lake Carnegie to the west of the Warburton Range. He had spent some years at a mission near Cosmo Newbery and was also recorded as being a stranger in Warupuyu (Tindale 1935a: 50). These two men were crucial members of the expedition team. They were labourers, interpreters, informants, recruiters of research subjects, and subjects themselves. And, as shall be discussed, Nijau in particular was key to Tindale securing privileged access to restricted ritual practices.

Although occurring 80 years ago and now beyond living memory, evidence of the inter-subjectivity of this remarkable event can still be found in the ethno-historical record in the form of field notes, photographs and audio recordings. Collectively these fragments provide considerable insight into the experiences of those present during the 3 weeks the expedition spent at Warupuyu, during which these strangers became familiar.

Particular attention is given here to social interactions around the scientists' cameras, and what these reveal about how differently positioned individuals viewed and categorised each other. Cameras were ubiquitously present during the expedition and were frequently at the centre of encounters between local people and the scientists. Between them the incomers carried five still cameras and at least one $16 \mathrm{~mm}$ cinefilm camera, and during the 3 weeks they took hundreds of photographs, exposed approximately 1,200 metres of film, and collected 271 crayon drawings. ${ }^{2}$ By the standards of the day this was an extraordinary enterprise, for at the time the filming of indigenous people for the purpose of anthropological research remained at best a marginal activity (Bryson 2002: 6). Many of the images taken in 1935 went on to receive wide circulation over a number of decades, mostly via reproduction in scientific and popular publications authored by Tindale and Mountford. Although replete with data about traditional material culture, it is remarkable how little their published images communicate about the relationships that developed between the scientists and their Ngaanyatjarra hosts during the expedition, or about desert sociality more generally.

By examining the moments of inter-subjectivity which facilitated the taking of photographs and film, this paper expands on the truncated impression of Ngaanyatjarra society and identity such images otherwise convey. The reconstruction of historical 'looking relations' (Lydon 2006: 243; McGrath 2010: 19) between the members of the expedition party and their Aboriginal hosts illustrates how an emerging familiarity that closed social distance and transcended normative identities facilitated frequent and often intimate acts of photography. The only documents from the expedition that were authored by Ngaanyatjarra people themselves - crayon drawings collected by Mountford-further add to understanding of the depth and breadth of the social geography in which the scientists were embedded. And yet this complexity was deliberately omitted from many of the films and photographs taken during the expedition, 
thus reducing their subjects to exemplars of tradition and negating the possibility of a uniquely Aboriginal modern identity.

\section{LOOKING AROUND THE CAMERAS OF STRANGERS}

A person's identity - the significant characteristics by which he or she is defined against others, either by themselves or by others - is a dynamic, performative, accumulative social fact that responds to the multiple and shifting social contexts through which they move. In her recent ethnography of Ngaanyatjarra literacy practices, anthropologist Inge Kral draws on Anthony Giddens' definition of identity as 'the creation of constancy over time, that very bringing of the past in conjunction with an anticipated future' (Giddens 1994 in Kral 2012: 262). Although lacking a sense of the performative aspects of identity emphasised by the likes of Goffman (1959), Kral's use of Giddens captures the extent to which social identity is an emerging narrative of individual social location grounded in habitus but inalienably connected to a wider sociality.

The figure of the 'stranger' is useful to discussions of identity, implying as it does unstable relationships of knowing and unknowing within a shared social space. Strangers have both social and spatial qualities; they are both proximate and distant (Dalley this volume; Simmel 1999: 185; Marotta 2012: 585). In their very immediacy they are recognised as being 'out of place', their presence confirming existence of the community to which they do not belong (Ahmed 2000: 49). During encounters between strangers, assumptions will be made and tested about the likely past, present and future trajectories of each other's lives in relation to particular places, the expected durability of the new relationship, and the potential opportunity costs of maintaining an involvement (Strathern 1990: 37; see Gell 1996: 322 for a discussion of opportunity costs in relation to social action). The stranger is a highly unstable social category; a person unknown may quite quickly become familiar, but they can never escape the fact that they once were, and may yet again be, a stranger.

As Redmond deftly articulates in relation to the evolution of relationships between Nyarinyin people and pastoralists in the Kimberley, cultural categories can be improvised and modified in response to the presence of strangers in order to establish 'a workable degree of relatedness against which differences and resistances are articulated' (Redmond 2005: 242). The well-documented strategy among Aboriginal people of assigning section or 'skin' categories to strangers extends kinship networks to the limits of the known world, turning relative strangers into 'strange relatives' and minimising their potential to undermine local social agency (Redmond 2005: 234).

Among Western Desert peoples, strangers are non-kin who are remarkable for their lack of relationship. This absence of relationship renders such individuals socially ambiguous and potentially dangerous and excludes their participation in many sacred and mundane aspects of life. The Ngaanyatjarra language has a number of different words for 'stranger'. One of these is munuyiiku, which literally translates as 'a completely foreign face' (Glass and Hackett 2003: 184). Another term is maliki, which is 
also used to describe to the ritual status of young men prior to their first initiation; until he gains adult forms of familiarity through initiation, a young man is a classificatory stranger with no claim on access to ritual knowledge (Tonkinson 1991: 58; E. Ellis, pers. comm. 29 Aug 2010). Maliki was also historically used to refer to nonAboriginal people (MacDougall 1964-71, Appendix 2: 3). ${ }^{3}$

With the likely exception of their Aboriginal guides, when Tindale's expedition party arrived at Warupuyu in the winter of 1935 they entered a social space with which they were unfamiliar and in which they had no established place; they were categorical strangers in an Ngaanyatjarra homeland. Contrary to the characterisation of the residents of the Warburton Range as isolated, unknowing and unknown, which is implied by Mountford's use of the phrase 'untouched by civilisation', contact in the Western Desert at this time in Australia's history was well underway. Desert people's individual experiences of colonisation were uneven and to an extent dependant on factors such as their age, gender and usual orbits of residence. Nonetheless, since the mid-1870s when Ernest Giles first traversed the region, families living in the Warburton Range area had encountered scores of explorers, prospectors, adventurers, missionaries and police (albeit in far fewer numbers than in more easily accessible areas of the central deserts and beyond) (Gara 2003: 15; McGrath 2010: 10).

Few early incomers stayed for any length of time, but they were not without influence. They brought with them and traded new technologies, foods and animals, each interaction expanding local understandings of developments in the world beyond immediate experience. The actions and attitudes of incomers towards Aboriginal people-sometimes violent, sometimes conciliatory, often ambivalent-were conspicuous, so much so that even Ngaanyatjarra who had not personally encountered walypala (white men) were well aware of their existence (Dousset 2002: 4). This was certainly the case in the Warburton Range, where by 1934 a small outpost of the United Aborigines Mission had been established at Milesia Well only a few kilometres from where Tindale's expedition camped at Warupuyu. At that time it was a fairly tenuous settlement, and the two young male missionaries stationed there engaged in subsistence trading as well as evangelism with locals, swapping flour, second-hand clothing and blessings for dingo scalps and rabbits (Tindale 1936: 483).

It is not surprising then that some of the Aboriginal people who Tindale and his colleagues met and photographed at Warupuyu in 1935 were familiar with many aspects of settler society and technology. Some spoke a little English and there is evidence that a few had travelled widely. The track that connected the Warburton Range to the town of Laverton had reportedly been used for some 30 years both by Aboriginal people and an array of incomers (Tindale 1935a: 528; Gara 2003: 84). Local kinship and knowledge networks fanned out far and wide. While at Warupuyu Tindale recorded a 'modern native song' that had been carried along these networks. The composer was an Aboriginal man from Laverton who had dreamt it while incarcerated in the Fremantle gaol (Tindale 1935a: 151). Many of the visitors to the Warburton Range during the 1920s and 1930s actively sought out Aboriginal people as guides. The demands on Ngaanyatjarra were such that at times there was competition and 
local men had a choice as to which group of incomers they would spend time with. Indeed, within a week of Tindale's expedition arriving at Warupuyu, two groups of prospectors turned up seeking guides for journeys further north and, despite attempts to prevent it, on more than one occasion Tindale lost valuable research participants to both prospectors and the missionaries (Mountford 1935b: 55; Tindale 1935a: 95, 141).

Nevertheless, although only 3 weeks in duration, the 1935 Warburton Range expedition (which at its peak involved over 100 Aboriginal people) was an intense event that brought with it unprecedented knowledge and experiences for Warupuyu families and Ngaanyatjarra people generally. This was the first time the Ngaanyatjarra people had been the subjects of in-situ investigation by colonial scientists. It was also the first time that anyone from this part of the Western Desert had been the subject of film recordings (McGrath 2010: 7). And while at the time the photography of people from the Warburton Range was not unprecedented, few incomers appear to have taken photographs and interactions around cameras were still novel. ${ }^{4}$ By the end of the expedition, however, all of those participating would be very familiar with the camera's gaze.

When the expedition party first arrived at Elder Creek there were about fifty individuals living in small family groups nearby. Concerned that these numbers were insufficient for the planned research activities, Tindale successfully negotiated with senior men to recruit additional people from the Rawlinson Range (220 km away to the north west) and Lake Carnegie (over $400 \mathrm{~km}$ to the east) (Tindale 1935a: 87, 181; Tindale 1963). It appears that one of the motivations for people to participate was news that a major initiation ceremony would be staged as part of the expedition. The provision of food by the expedition, meat in particular, helped grease (literally) the social relationships that enabled this to happen (Tindale 1935a: 197, 201; see Redmond this volume, for more about the significance of meat in facilitating intercultural engagements).

Almost immediately upon their arrival the scientists began actively developing relationships with local families and recording aspects of people's daily lives. Unlike earlier incomers such as overlander Michael Terry (who was notorious for refusing to allow Aborigines into his camp), Warburton people were welcomed into the domestic space of the expedition. Within a few days all members of the expedition party had been given section names by senior men, embedding them in the local kinship network and placing them in new social relationships to each other as well as their Aboriginal hosts. This created a hierarchy of social seniority among expedition members that almost completely inverted the professional structure of the team. Tindale, the expedition leader, was required to call Mountford, the least experienced of the researchers, mama (father). Tindale was also to call Stocker kamuru (mother's brother), Hackett maritji-kurta (wife's elder brother), and Nijau Jack maritji-malango (wife's younger brother) (Tindale 1935a: 522). According to Tindale, the scientists applied their skin names fastidiously even when addressing only each other. Familiarity quickly developed between locals and incomers, and before the end of the first week Tindale wrote, 'It is pleasant to feel that people have taken us so closely and 
intimately into their lives, if even only for a few days' (Tindale 1935a: 282, 522). The benefits of establishing such kinship relationships, however, extended beyond just the sentimental. As Tindale would have been well aware, such relations were crucial to enabling access to a wide range of social knowledge that might otherwise have remained out of reach.

The scientists' pursuit of local knowledge over the following few weeks was, by any measure, intense. Tindale documented that a total of 98 Aboriginal people participated in the expedition research activities, 54 of whom were subjected to an 'anthropometric routine' which involved being interviewed by Tindale, photographed by Mountford and measured by Hackett (Tindale 1936: 483). Samples of head, face and pubic hair were also acquired. The use of cameras was prolific and a comparison of photographs from across a number of archival collections reveals that multiple cameras were frequently used to document the same activity or person. ${ }^{5}$ There was a degree of competition between the scientists over access to photographic subjects, and this was likely observed and understood by those they were photographing (Tindale 1951: 44).

Tindale, an experienced fieldworker and photographer, concentrated his visual attention almost exclusively on Aboriginal people, taking photographs at a distance to record the social dynamics of large group interactions such as the ceremonial greeting of a group of strangers, while at other times moving closer to create more intimate portraits of individuals and material culture (see Tindale 1935b). Mountford, by comparison, was a practiced photographer but had little research experience. ${ }^{6}$ And yet he was far more inclined than Tindale to document the research process itself, and took a number of photographs illustrating the encounters between locals and scientists around the camp (Mountford 1935c). A number of examples of such images are shown in Figure 2.

Hackett also had a camera and took a number of 'relaxed and intimate' portraits that, Philip Jones suggests, were enabled to a degree by the 'touching relationships' Hackett established with people during medical examinations and anthropomorphic measurements (Jones 2011: 100). Hackett's photographs were never published, but he included them in a letter to his family that took the form of a photographic album (Hackett 1933-34; Hackett 1937). The filmmaker Stocker, who had accompanied Tindale on two previous expeditions, went to extraordinary lengths to secure footage of hunting, ceremonies and general daily activities, and he also took many still photographs (Tindale 1935a: 189, 191; Tindale 1935b). ${ }^{7}$ Shooting in arduous conditions and often for hours on end, Stocker set up and repeatedly filmed numerous scenes that were later edited to create the seamless, natural action of the resulting expedition film (Stocker 1935). ${ }^{8}$ Over the course of the 3 weeks, the scientists developed a twocamera approach to filming that allowed for cutting between camera angles during editing (Leigh 1988: 84; Bryson 2002: 5-6).

The intensity with which the scientists used film and photography and the frequency with which they engaged in re-enactments exemplifies the practices of the 'proto-modern' anthropology of this period, that deployed cameras as a means to 


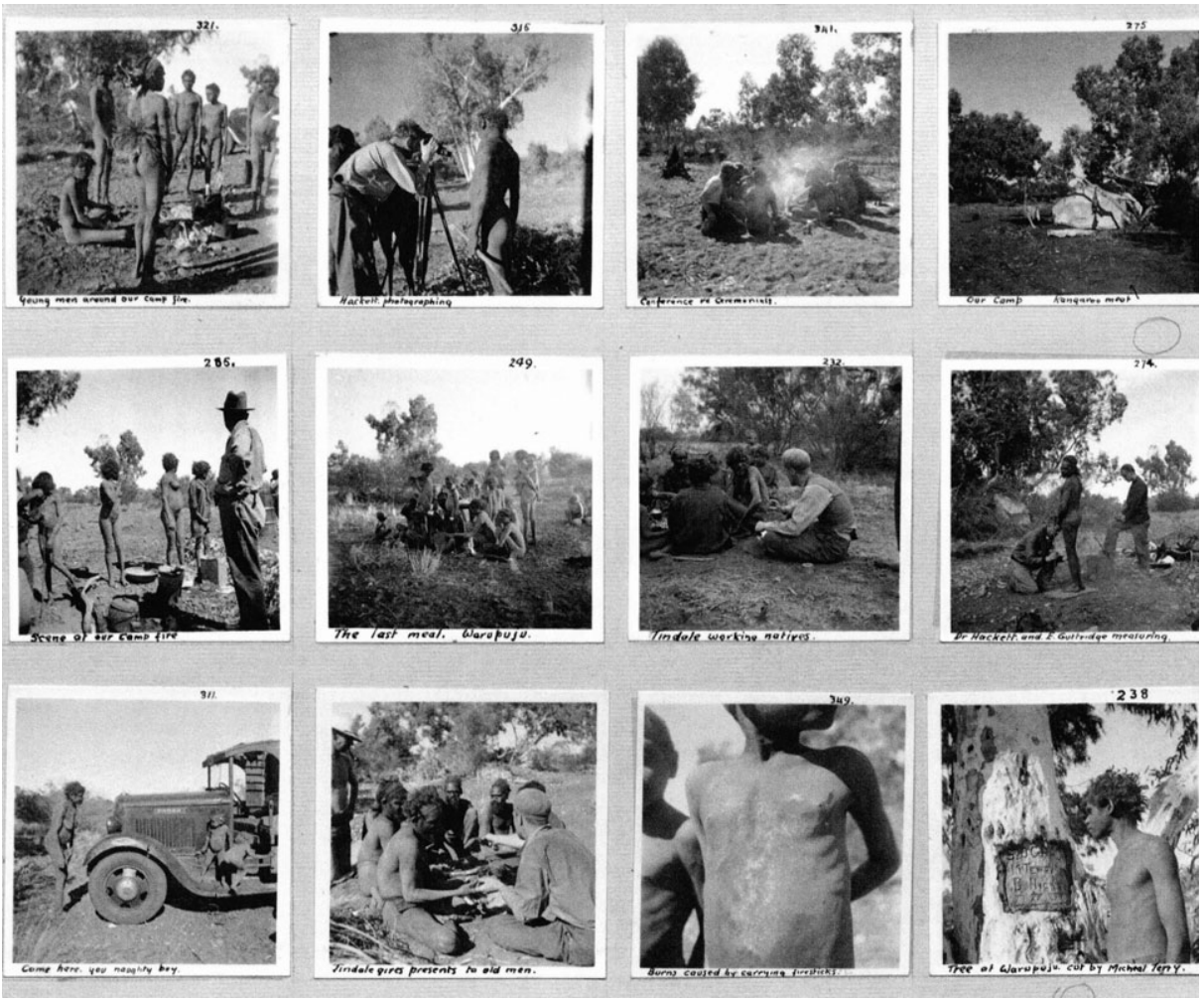

Figure 2 A page from C. P. Mountford's Warburton Range expedition album. Images show activities such Tindale taking notes, Hackett photographing, Hackett and Gutteridge conducting measurements, Tindale in consultation with senior men, and the expedition's last meal. (Mountford 1935c: 15). Courtesy of the State Library of South Australia.

scientifically visualise an unseen or unseeable cultural past (Edwards 2001: 157). Premised on assumptions about inevitable loss and motivated by the disappearance of desired subjects, re-enactment photography pursued the 'resurrection of a fractured cultural wholeness' (Edwards 2001: 157-8). Lurching between science and theatrepart performance, part history-Edwards characterises ethnographers who engaged in re-enactment photography not as objective observers but as active cultural participants who facilitated and directed cultural continuity (Edwards 2001: 169).

It is interesting to consider the likely disjunct between the scientists' own understandings of the impacts of their looking behaviours, and how these behaviours were actually received by the people of Warupuyu. Among Western Desert people, acts of looking are highly regulated and play a very significant role in the enactment of differential social relationships. Meetings between strangers, intergenerational kinship relations, sexual relations, the practice of ceremony and the revelation of ritual knowledge are all fundamentally shaped by acts of looking. Moreover, looking behaviours are crucial to the demarcation of private and public space, and the expression of kurnta 
(respect). In contrast to an assumed innocuousness of the gaze epitomised by sayings such as 'I was only looking' or 'You can look but you can't touch', looking among desert people is an active, not a passive, social behaviour that produces physical effects (McGrath 2010: 52). Looking can be offensive or dangerous, and staring - an act of intense and uninterrupted looking - has the potential to be deadly (McGrath and Brooks 2010: 136).

The Ngaanyatjarra language includes numerous evocative phrases that describe the act of staring and those who do it: papulanku (to look intently at someone or something unknown; to look intently at someone without recognition) ${ }^{9}$; nyaku tarrkalku (lit. 'looking until there is nothing left but bones'); kurunyaku (lit. an 'eyelooker'); kurutarltu (lit. having 'swollen' or dilated eyes); kurukayili (lit. having 'northern eyes'); and kurumamu (lit. having 'devil eyes') (E. Ellis, pers. comm. 29 August 2010; Glass and Hackett 2003: 91, 297). The Aboriginal English colloquialism of a 'hard look' has been used by Ngaanyatjarra people in more recent times to describe the unwelcome gaze of a stranger's camera judged to be lacking compassion or respect (McGrath and Brooks 2010: 136). That there are so many related expressions for undesirable acts of looking speaks to the importance of looking behaviours in the mediation of interpersonal relationships among members of desert Aboriginal societies, and particularly in the enactment of encounters with strangers.

Although numerous entries in Mountford's and Tindale's field notes acknowledge a degree of social tension created by their multiple acts of unmitigated looking, at times both men confused their subjects' awareness of being observed with their limited understanding of the technology being used. Non-responsiveness to cameras was consistently characterised as passive ignorance, which overlooked the possibility that individuals were, in fact, actively ignoring them: 'The natives here do not understand the camera and one can push the camera right up against their face and they still go on working' (Mountford 1935b: 62). Operating in a social environment where acts of looking were so crucial to the mediation of inter-subjectivity, it is difficult to imagine that any Ngaanyatjarra person could have been unaware of the observational intent of the scientists' cameras, even if they had little concept of their technical operation or representational reach.

The characterisation of the subjects of such ethnographic photography as passive, unwilling or insensitive to the power and social potential of re-enactment is, Edwards argues, misguided (Edwards 2001: 173). There is ample evidence to suggest that in this instance, the people of Warupuyu were well aware of the scientists' observational intentions and at times actively cooperated to facilitate photography through recreation of social action, encouraging the taking of photographs and insisting that details of particular activities be recorded (Mountford 1935b: 63). The scientists also documented many instances where people actively resisted being photographed, or objected to having their appearance or immediate surrounds manipulated for the camera. Women in particular seem to have been reluctant participants (Mountford 1935b: 83, 133). 
And yet, driven by a concern that technological knowledge would interfere with the naturalism of people's behaviour, the scientists took deliberate steps 'not to let them see inside the cameras and tell them anything about them at all' (Mountford 1935b: 62). They also requested that clothing and other items such as blankets and metal objects be removed from the view of the camera:

There is not much clothes [sic] in the camp but what they are [is] a dashed nuisance. One man has a cap, another a shirt, one girl has a coat while [an older woman] rejoices in what looks like a lace curtain ... The old man has both trousers and a coat which he is not inclined to remove when we want our standard portraits. (Mountford 1935b: 65)

Mountford was so concerned about the appearance of clothing in photographs that during filming of a ceremony he refused to allow Peter Pitawara to participate unless he went both naked and barefoot. Pitawara, who had spent some years living at Mount Margaret mission and who regularly wore clothes and shoes, agreed to the request and according to Mountford, 'suffered terribly' (1935b: 149).

\section{THE INITIATION OF NIJAU JACK, A FAMILIAR STRANGER}

The ritual event for which Pitawara was denied the comfort of shoes was the first of two initiation ceremonies staged during the expedition. ${ }^{10}$ From the outset of the expedition, Tindale had declared a desire to document a local initiation and within a week of arrival had broached the subject with the senior men of Warupuyu. The men advised that although there were no suitable candidates present, they would perform the ritual if Tindale's young guide, Nijau, would submit (Tindale 1935a: 215). We have no insight into how Nijau responded to this invitation, but it is clear that Tindale did not hesitate to accept the deal. When the proceedings took place they were witnessed by Tindale and filmed and photographed by Stocker and Mountford. ${ }^{11}$

Little is known of Nijau's personal history either prior to or following the expedition. Originally from Tjikarli, he had spent a number of years living at Cosmo Newbery and was described by Mountford as 'almost completely detribalised' and as having been 'under mission influence all his life' (1935a, sheet 17; 1935b: 48). Recruited in Laverton on the understanding that he was 'fully initiated', it had become apparent in the expedition's first few days at Warupuyu that this was not, in fact, the case. When working with Mountford to collect and interpret local 'art', Nijau reportedly became 'diffident and hesitating' in the presence of older men, who hid from him their drawings of tjukurrpa (mythological dreaming tracks). Mountford described him as still 'tribally a child' with limited access to certain categories of knowledge (Mountford 1938: 112).

Contrary to Tindale and Mountford's assumptions about his stranger status, however, Nijau was likely known to the people of Warupuyu (even if he had never before met them) and the senior men's desire to see Nijau submit to initiation driven by socially internal factors. According to anthropologist David Brooks, who has undertaken extensive genealogical and oral history research with Warburton families (see 
Brooks 2012), there are long-standing historical connections between Warburton Range and Lake Carnegie and a number of people travelled from Tjikarrli to participate in the 1935 expedition. It was the first time in many years that they had made the journey due to an enduring conflict over the theft of someone's wife. Brooks speculates that the events of the expedition were sufficiently extraordinary to overcome this old wound and that Nijau's submission may have played a central role in the reconciliation of this argument (D. Brooks, pers. comm. November 2011).

The social consequences of initiation for Nijau personally appear to have been profound, extending beyond the period of the expedition and precipitating a significant transformation in his local social identity that opened doorways to new kinds of intra-cultural relationships. This transformation was interpreted by Mountford, however, through an inter-cultural (rather than intra-cultural) lens, with Nijau's newly-granted access to a world of sacred knowledge characterised as representing a transition from outside Ngaanyatjarra society to within it:

He no longer played with the boys or approached the men with downcast eyes ... but associated freely with the elders, notably proud of his new status ... No longer did the men turn their sheets of drawings face downward, but willingly explained through Nijau the meaning of the symbols on the sheets of drawings (Mountford 1938: 112-3).

Thus Nijau reached full tribal membership. If Nijau had not been [initiated], he would have lived his life an outcast from his tribe... (Mountford 1938: 112-3).

Mountford based his analysis of Nijau's transformation on a series of crayon drawings the young man made; some before his initiation, some afterwards. The first featured many Western objects; the latter more classical Aboriginal designs, leading Mountford to conclude that the stylistic and subject differences between them indicated a profound shift in identity from detribalised outcast to tribal insider. The implication is that, prior to his initiation and as a result of his time spent living on a mission, Nijau was an estranged individual, no longer embedded in the natural attitude of his tribal relatives. Moreover, his analysis assumes that the sociality of this 'tribal' domain was defined by a traditional materiality and iconography, and thus that an Aboriginal person's identity at this moment in time was inextricably linked to their material, rather than social, circumstances.

The handful of crayon drawings Nijau made for Mountford are indeed remarkable but the social identity they represent is, I suggest, far more complex than the inside/ outside dichotomy posited by Mountford. It is true that Nijau's pre-initiation drawings depict a variety of non-Aboriginal items and people, including a train, an aeroplane, an axe, a bucket, a bullock, a cauliflower, a windmill, and a policeman (Mountford 1935a; sheets 30, 31, 51, 52; see Fig. 3). But alongside these objects Nijau drew others that were explicitly indigenous in origin: boomerangs, woomeras, fighting sticks and spears. And yet Mountford judged these illustrations to be 'purely European', and 'such as any white child in the upper classes of a primary school might have produced' (Mountford 1938: 112). 


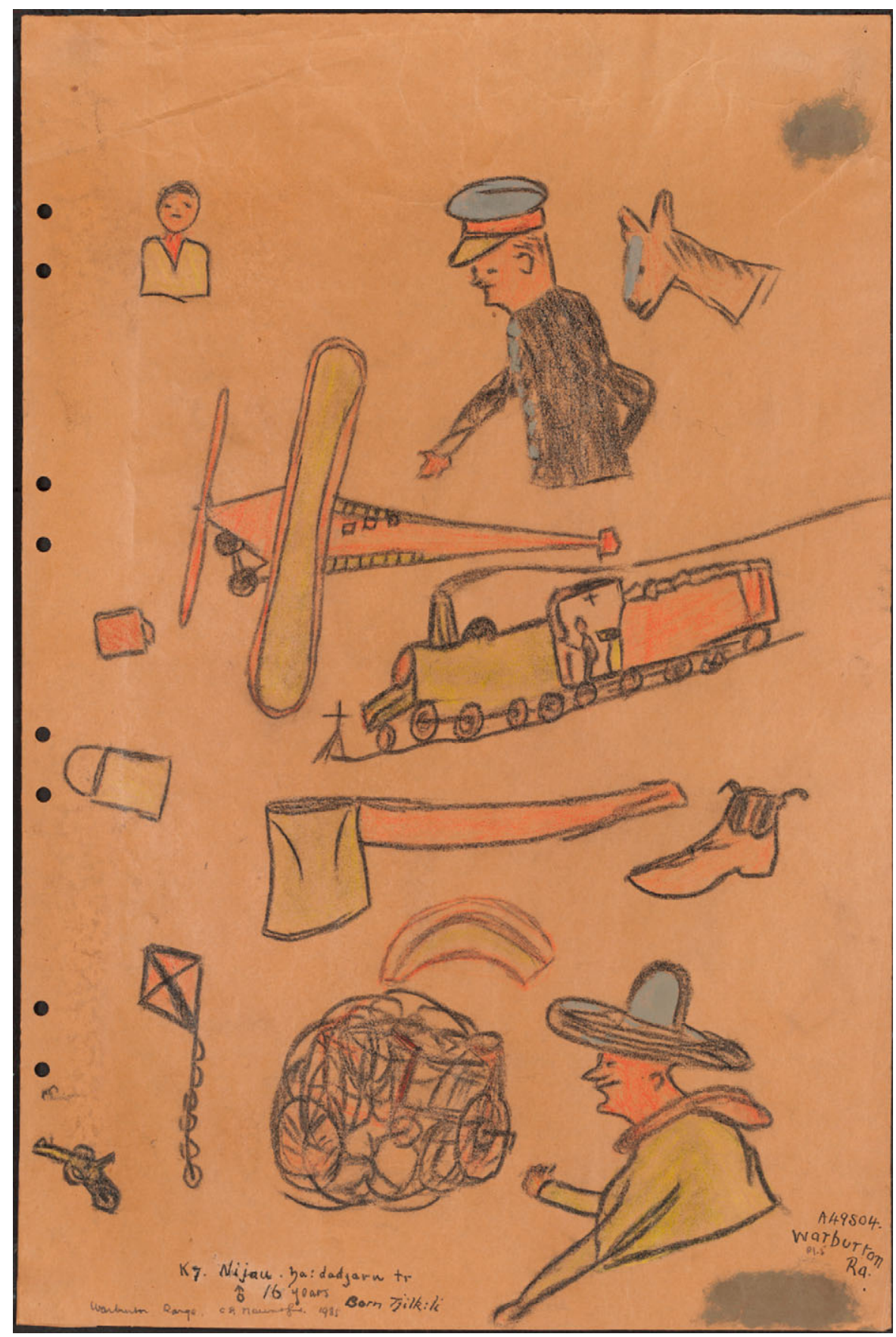

Figure 3 Crayon drawing by Nijau Jack (Mountford 1935a, sheet 30). Courtesy of the South Australian Museum. 
Closer examination of elements within these drawings reveals that Nijau's attention to Western objects was shaped by a distinctively contemporary sensibility that nevertheless remained fundamentally grounded in an Aboriginal worldview. The most striking examples take the form of Nijau's sketches of a monkey and a bucket shown in Figure 4 (Mountford 1935a, sheet 52). Mountford's annotations alert us to the fact that this isn't just any monkey, but a monkey who at the time was on exhibition at the Kalgoorlie Zoo. Resembling as it did the embodiment of the mythical and much feared mamu wati (devil man), this monkey reportedly fascinated locals and was famous among Aboriginal people throughout the region. Rather than signifying the loss of his Aboriginal sociality, I suggest that Nijau's monkey was indicative of his ongoing orientation towards a Ngaanyatjarra world view. The monkey was of interest to Nijau because of its 'mamu-ness', not because of its 'monkey-ness'. And yet it was Nijau's experiences moving within settler society that enabled his first-person knowledge of the monkey. Far from being indicative of a 'de-tribalised' identity, Nijau's mamu monkey-man is simultaneously indicative of both his cosmopolitanism and traditionalism.

The drawing of a small yellow bucket that appears immediately below the Kalgoorlie monkey harbours similarly complex meanings. This is not just any bucket, but is identified precisely by Mountford as 'a bucket with pee in it' (Fig. 4). The practice of collecting urine in buckets at settlements without plumbing was an approach to managing human waste that would have been remarkable to people more accustomed to subsistence lifestyles and for whom body fluids were potentially dangerous. As with the monkey, the bucket of pee suggests that Nijau had a deep understanding of Ngaanyatjarra norms and the extent to which they were challenged by the material practices of settlers.

In his desire to demonstrate the categorical return of an estranged native to his tribal roots, Mountford failed to recognise that, despite a period of residence at a mission, Nijau had retained a place within a complex, enduring and widespread kinship network that extended well beyond the Warburton Range. The fact that the old men of Warupuyu insisted on his initiation suggests that Nijau was not socially different or distant, but rather was socially eligible. He may have been a maliki (stranger) in terms of his social maturity, but he was not socially unknown. And yet, despite the scientists' extensive documentation of Nijau and the ceremony that facilitated his transformation, the nuances of this young man's social identity remained invisible to the camera, obscured by a confusion of social and geographical distance.

Nowhere is this confusion more apparent than in a number of photographs of Nijau taken by Mountford and Hackett that show the young man painting traditional designs on his body and face using black powder from a puffball fungus (Mountford 1935c: 6; Jones 2011: 113). In these photographs 'Jack' [Nijau] appears against a backdrop of low-lying desert foliage, naked from the waist up and wearing a headband made of string. The images bear no trace of Nijau's engagement with settler society that so disturbed Mountford and led him to conclude that Nijau was a 'detribalised' stranger; on the contrary, the image was later generically captioned and used to illustrate this particular traditional cultural practice. Whether Mountford considered this 


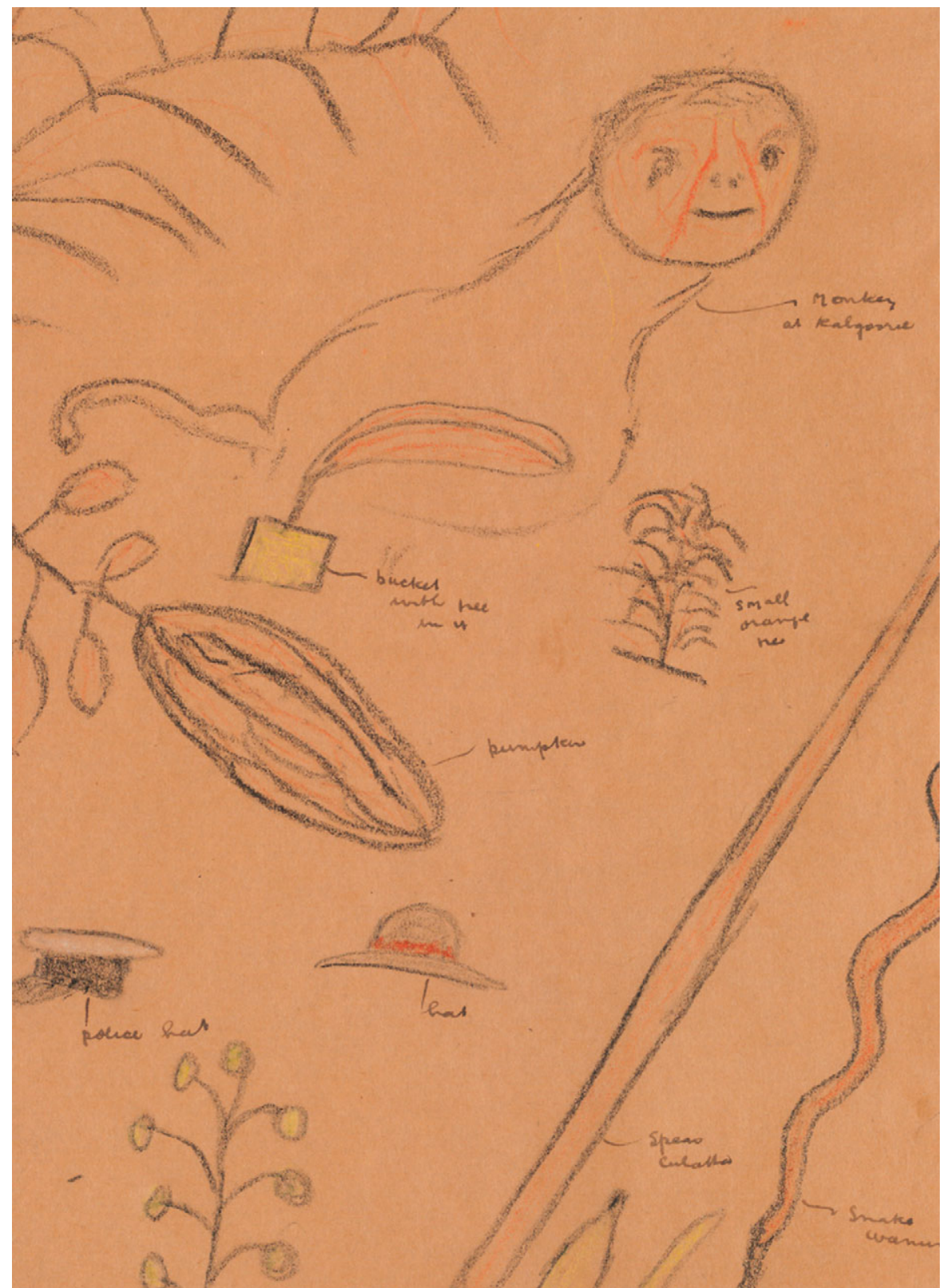

Figure 4 Detail from Nijau's drawing showing both the 'monkey at Kalgoorlie' and a 'bucket with pee in it' (Mountford 1935a, sheet 52). Courtesy of the South Australian Museum.

image to be a form of re-enactment is uncertain; what is clear, however, is the extent to which Nijau was capable of performing 'tradition' as well as 'modernity' and yet how the inherent flexibility of his social identity evidenced by this capacity was obscured by the essentialising tendencies of both the photographer and the medium. 


\section{PHOTOGRAPHY AND THE REPRESENTATION OF STRANGERS}

As demonstrated by the interpretive fate of some of the images taken of Nijau during the Warburton Range expedition, photographic mediums have the potential to grossly exaggerate the social orientations and competencies of both their subjects and their makers. The biographies suggested by photographs are highly dependent on the context of their viewing (Edwards 2001: 14); without the intervention of text or direct experience to anchor meaning and guide interpretation, photographs (and to a lesser extent film) flatten out understandings of identity through a truncation of the temporal depth of an individual's social geography. This is particularly true in relation to subjects who are unfamiliar. A photograph's constant reinforcement of a particular person-place relationship within a particular moment in time reifies the dynamics of identity and pushes subjects towards static, constrained and, at times, misleading social categories. And yet the innate naturalism of the photographic medium and the proximity it implies between photographer and subject suggests authentic social insight and lends itself to a particular kind of historical authority that serves anthropology well (Edwards 1992: 6).

After Nijau's initiation and towards the end of expedition's time at Warupuyu, people's interest in the scientists appears to have waned; with more than 50 people camped in the vicinity, likely too had the local availability of resources such as food, firewood and water. Cooperation was withheld and there were days when the scientists were unable to secure anyone to interview or photograph (Mountford 1935b: 82, 84). Despite this withdrawal, a level of trust and intimacy had developed between the scientists and local families during their stay, and when the expedition broke camp they were warmly farewelled: 'The men came swarming around, held us by the hands and expressed the hope that we would come back again, we felt quite loath to part with them' (Tindale 1935a: 425).

The event left an enduring impression on local families and stories about the expedition continue to circulate among older Ngaanyatjarra people some 80 years on. One senior man who has lived in the region all his life and who was a baby in 1935 was with his parents at Warupuyu that winter. Although he himself remembers nothing, his mother and father (who were both photographed by Tindale, Mountford and Hackett) told stories about their experiences for many years afterwards. These stories highlighted the extraordinary number of Aboriginal people present, the dances that took place, the journeys in the scientists' truck, and the abundance of meat. Significantly, they also spoke of the white men's cameras (P. West, pers. comm. 28 May 2009). The experience of being photographed had been a memorable one.

What the families of Warupuyu could not have known as they waved the expedition truck goodbye in 1935 was that in the years and decades that followed hundreds of images of them taken during those three short weeks would be used by the scientists to illustrate their own stories of this expedition, and that they would be seen by countless other people around the world. With few other images of Ngaanyatjarra people in circulation until the $1960 \mathrm{~s},{ }^{12}$ the representations of life at Warupuyu promoted by 
Tindale, Stocker and Mountford carried uncontested ethnographic authority for more than three decades. Throughout his career Tindale used photographs of Ngaanyatjarra people taken during the 1935 expedition to illustrate traditional Aboriginal lives in both popular and scholarly books and articles. Almost half of the 94 images of Aboriginal people reproduced in Tindale's Aboriginal Tribes of Australia (1974) are of people from Warupuyu; a photograph of Warupuyu initiates (one of whom may be Nijau) appears in his children's book, The Australian Aborigines (1971). Mountford's use of Warupuyu images most notably included a 1946 lecture tour of the United States during which he shared photographs from the expedition with ' 55,000 Americans in 55 lectures' (Mountford 1928-1948, Vol. 4, Herald Sun 17 June 1946). And Stocker's Warburton Range expedition film was shown on academic lecture circuits up until the 1970s; both Tindale and Mountford reportedly aspired to producing a more accessible version so as to reach an even larger audience (Leigh 1988 in Bryson 2002: 6).

The images Tindale and Mountford shared with outside audiences did not reflect any of the familiarity that evidently developed between them and the families of Warupuyu during the 3 weeks of this expedition. None of the scientists appear in their published photographs, and few of the Aboriginal people shown were named. All traces of people's engagement with aspects of 1930s settler Australia such as those illustrated in Nijau's drawings were selected out of published images; few clothes and no billy cans, blankets, shoes or non-Aboriginal people appear in any of the published photographs of the expedition. What appears in its place is a representational confidence that renders the actual messiness, confusion and intimacy of colonial encounter invisible (Thomas 1994: 15). In turn, the people of Warupuyu who had, over the 3 weeks, become friends and familiars, were once again relegated to the category of stranger. After all, as Ahmed has observed, anthropological knowledge is predicated on 'the knowability of strangers and the desire to accumulate knowledge of those who are already recognised as strangers' (2000: 49).

A consequence of this narrow portrayal of Warupuyu lives is the curtailing of the extent to which the people of the Warburton Range are historically understood to have been embedded in a regional social network that extended well beyond their immediate locale. Instead, the scientists presented a picture of Ngaanyatjarra life that was highly localised and insulated from external sociality, including from other forms of indigenous sociality. Tindale was not ignorant of or indifferent to Aboriginal people's active engagement with many different aspects of contemporary Australian society. ${ }^{13}$ What is remarkable, however, is that neither he nor Mountford showed any inclination to illustrate such insights using film or photographs. With the removal of all traces of familiarity and engagement with settler society and the reinstatement of exemplary strangeness, a model of Aboriginal society was promoted that left no room for the complex identities of individuals such as Nijau.

As the story of Nijau demonstrates, it is possible to deconstruct such deliberate strangeness through a close examination of archival photographs, films and drawings read in conjunction with their authors' accounts of the moments of sociality in which they were created. Nijau's drawings and biography together subvert the historical 
purchase of the traditional-insider/modern-outsider binaries that are suggested by the published representations of Mountford, Tindale and their colleagues. What emerges in place of these binaries constitutes a significant contribution to understandings of locally-specific modern Aboriginal subjectivities of the kind recently called for by Eickelkamp (2011: 131, see also Kowal this volume): a nuanced account of the mutability of identity and the endurance of belonging in the face of social disruption, geographical dislocation and material change.

\section{POSTSCRIPT: CONTEMPORARY NGAANYATJARRA MODERNS}

Among Ngaanyatjarra people today the networked infrastructure of kinship that was rendered invisible in early ethnographic accounts of Warupuyu sociality has endured and remains grounded in place. The small mission at Milesia Well also endured and eventually became the town of Warburton, now the major residential centre of the Ngaanyatjarra region. Recent research by David Brooks suggests that 12 of the 23 family groups who participated in the 1935 expedition still exist (D. Brooks, pers. comm., July 2011); to date, however, Nijau's contemporary family has not been identified.

Elements of Nijau's complex social identity can be seen in the lives of young people living at Warburton today, many of whom take great pride in their 'Ngaanyatjarra-ness' and yet collectively position themselves 'at the intersection between tradition and modernity' (Kral 2012: 253, 257). They are forging identities 'based not on models reproduced within cultural memory, but on a synthesised multiplicity of influences' (Kral 2012: 236). Like Nijau before them, their contemporary experiences are not taking them outside of Aboriginal sociality but rather are resulting in a reworking of the intergenerational social frameworks in which they, their parents and their grandparents all operate (Kral 2012: 232). Many of these transformations are increasingly visible as young Ngaanyatjarras engage with new technologies and cultural forms to articulate the conditions of their lives for both external and internal audiences. The effect is a continuing insertion of individuality and familiarity into a public space in which their people have historically been portrayed as distant strangers.

Please send correspondence to Pamela Faye McGrath: pamela.mcgrath@aiatsis.gov.au

\section{NOTES}

1 Tindale had previously conducted similar research expeditions with Aboriginal people living near MacDonald Downs, N.T. (1930); Cockatoo Creek, N.T (1931); Mt Liebig, N.T (1932); Mann and Musgrave Ranges, S.A (1933); and Ooldea, S.A. (1934).

2 The majority of these are held in collections housed by the South Australia Museum (Tindale and Stocker) and State Library of South Australia (Mountford and Hackett). In the Mountford collection alone there are 10 albums containing hundreds of photographs of sacred sites and objects, portraits of Aboriginal people, food gathering and preparation, children's games, gesture language and ceremonial activities. The collection also includes extensive recordings of two important initiation rites. Many sound recordings of songs and language were also obtained. 
Restricted images and field notes held in these collections have not been viewed and are not discussed at any length here.

3 Native Patrol Officer Walter MacDougall documented in 1956 that some Ngaanyatjarra people referred to 'whites' as 'maliki (strangers)'.

4 By 1935 Aboriginal people from this area had been photographed, albeit somewhat sporadically, by Michael Terry, R.M. Williams and the UAM missionaries. For more information about the history of the photography of Ngaanyatjarra people by incomers, see McGrath 2010, pp. 59-98.

5 To give but one example, in his journal Mountford noted an episode where Tindale, Stocker and Mountford all simultaneously photographed a solitary woman collecting seeds (Mountford 1935b: 58).

6 In 1923 Mountford won almost every category of a photography competition run by the 'Oval Improvement Committee' of Darwin, including most original study, best photograph taken outside the Northern Territory, best seascape, best landscape, best Aboriginal study, and best fruit photograph. By 1925 he was a member of the Adelaide Camera Club, and in the following few years held position of both Vice-President and President. By 1928 two of his photographs (both of non-Aboriginal subjects) hung in the Art Gallery of South Australia (Mountford 1928-48, pp. $1,3,9)$.

7 Stocker's photographs are included in Tindale's collection of expedition photographs. See Tindale 1935b.

8 For example, a scene in the final cut of the expedition film shows two young boys appearing to successfully kill a number of small birds at a soak in the creek by throwing sticks at them. The birds had, in fact, been shot by someone else and were given to the boys after they failed to kill the birds themselves (Mountford 1935b: 52).

9 The name for the locality of Blackstone as well as a nearby rockhole, Papulankutja, is derived from the term papulanku, 'to look without recognition'. The name relates to a tjukurrpa that runs through the area which tells the story of wati kutjara (two men). These two men were walking together from the west when they came across the Blackstone Range. One man decided to walk along the range to the north, the other walked along the range to the south. When they saw each other from a distance, they did not recognise each other: 'Hey, who is that strange man over there? What is he doing looking at me?!?' The story is a comedy of errors that draws attention to the significance of recognition of others. I thank David Brooks for these observations (D. Brooks, pers. comm. 13 September 2010).

10 The timing of the second initiation, which was held only the day before the expedition broke camp to return to Laverton, was delayed until men in the appropriate father-in-law relationship to the initiates arrived from an unnamed locale some 4 days walk away, and the ceremonies continued even after the scientists had left (Tindale 1935a: 267).

11 The images from this ceremony are restricted for viewing by men only and have not been reviewed as part of this research.

12 Significant anthropological research with Ngaanyatjarra speakers did not occur again until almost 25 years later when Ronald and Catherine Berndt visited in 1957 during a government investigation into living conditions on the reserve (see Berndt 1957; McGrath and Brooks 2010).

13 See, for example, The Advertiser 1935, 'Among Natives in Desert Wilds', September 25, and The Advertiser 1935, 'Native Life at Oasis Camp: Strange Ways of White Fellow', 30 September in Tindale 1935a, pp. 530-2. 


\section{REFERENCES}

Ahmed, S. 2000 Who knows? Knowing strangers and strangerness, Australian Feminist Studies 15(31): 4968.

Berndt, R. M. 1957 The 'Warburton Range' controversy, The Australian Quarterly 29(2): 29-44.

Brooks, D. 2012 Dreamings and connections to country among the Ngaanyatjarra and Pintupi of the Australian Western Desert. PhD thesis, Australian National University, Canberra.

Bryson, I. 2002 Bringing to Light: A History of Ethnographic Filmmaking at the Australian Institute of Aboriginal and Torres Strait Islander Studies. Canberra: Australian Institute of Aboriginal and Torres Strait Islander Studies.

Dousset, L. 2002 Politics and demography in a contact situation: the establishment of the Giles Meteorological Station in the Rawlinson Ranges, West Australia, Aboriginal History 26: 1-22.

Edwards, E. 1992 Introduction, in (ed.) E. Edwards Anthropology and Photography. London: Yale University Press, pp 3-17.

Edwards, E. 2001 Raw Histories: Photographs, Anthropology and Museums. Oxford: Berg.

Eickelkamp, U. 2011 Changing selves in remote Australia? Observations of Aboriginal family life, childhood and 'modernisation', Anthropological Forum 21(2): 131-51.

Gara, T. 2003 Explorers and prospectors, in (ed.) J. Turner Trust. Alice Springs: Warburton Community Incorporated, pp 14-22.

Gell, A. 1996 The Anthropology of Time: Cultural Constructions of Temporal Maps and Images. Oxford: Berg.

Giddens, A. 1994 Living in a post-traditional society, in (eds) U. Beck, A. Giddens, S. Lash Reflexive Modernization: Politics, Tradition and Aesthetics in the Modern Social Order. Cambridge: Polity Press, pp 56-109.

Glass, A. and D. Hackett (eds.) 2003 Ngaanyatjarra and Ngaatjatjarra to English Dictionary. Alice Springs: IAD Press.

Goffman, E. 1959 The Presentation of the Self in Everyday Life. New York: Angkor Books.

Hackett, C. J. 1933-34 AA122/01: A letter about an unknown world, or A trip into North Western South Australia. Cecil John Hackett Collection, Adelaide: South Australian Museum.

Hackett, C. J. 1937 AA122/04: A Third Letter from Australia, Adelaide, South Australia to the Warburton Ranges, W.A. via Ooldea, A.A., Kalgoorlie and Laverton, W.A. July and August 1935, Vol. i-iii, London 1937. Cecil John Hackett Collection, Adelaide: South Australian Museum.

Jones, P. 2011 Images of the Interior: Seven Central Australian Photographers. Kent Town, South Australia: South Australian Museum.

Kral, I. 2012 Talk, Text and Technology: Literacy and Social Practice in a Remote Indigenous Community. Bristol, UK: Multilingual Matters.

Leigh, M. 1988 Curiouser and Curiouser, in (ed.) S. Murry Back of Beyond: Discovering Australian Film and Television. North Sydney: Australian Film Commission, pp. 70-89.

Lydon, J. 2006 Eye Contact: Photographing Indigenous Australians. London: Duke University Press.

MacDougall, W. 1964-1971 Series 2030, Item 1965/0066: Warburton Ranges - Native Matters. Perth: State Records Office of Western Australia.

Marotta, V. 2012 Theories of strangers: introduction, Journal of Intercultural Studies 33(6): 585-90.

McGrath, F. 2010 Hard looking: A historical ethnography of photographic encounters with Aboriginal families in the Ngaanyatjarra Lands, Western Australia. PhD thesis, Australian National University, Canberra.

McGrath, F. and D. Brooks. 2010 'Their Darkest Hour': the films and photographs of William Grayden and the history of the 'Warburton Range controversy' of 1957, Aboriginal History 34: 115-41.

Mountford, C. P. 1928-1948 PRG 1218/31/1: Press Cuttings - 8 Volumes. C.P. Mountford Collection, Adelaide: State Library of South Australia.

Mountford, C. P. 1935a AA346/15/1: Crayon drawings relating to the Warburton Range expedition, Western Australia, 1935. Board of Anthropological Research Collection, Adelaide: South Australian Museum.

Mountford, C. P. 1935b PRG 1218/6/1 University Expedition to Warburton Ranges, W.A. 1935 - Journal. Mountford Collection, Adelaide: State Library of South Australia.

Mountford, C. P. 1935c PRG 1218/6/3: University Expedition to Warburton Ranges, W.A. 1935 - Photographs. Mountford Collection, Adelaide: State Library of South Australia.

Mountford, C. P. 1938 Contrast in drawings made by an Australian Aborigine before and after initiation, Records of the South Australian Museum 6(2): 111-14. 
Redmond, A. 2005 Strange relativities: mutualities and dependencies between Aborigines and pastoralists in the northern Kimberleys, in Figuring the Intercultural in Aboriginal Australia, M. Hinkson and B. R. Smith (eds) Oceania 75(3): 234-46.

Simmel, G. 1999 The stranger, in (ed.) G. Lemert Social Theory: The Multicultural and Class Readings. Boulder, C.O: Westview Press, pp 184-9.

Stocker, E. O. 1935 Series AA346/09/10: Films recorded during the Board for Anthropological expeditions, 1926-1966, Warburton Range, Western Australia, 1935. Board for Anthropological Research Collection, Adelaide: South Australian Museum.

Strathern, M. 1990 Artefacts of history: Events and the interpretation of images, in (ed.) J. Siikala Culture and History in the Pacific. Helsinki: The Finish Anthropological Society, pp 25-44.

Thomas, N. 1994 Colonialism's Culture: Anthropology, Travel and Government. New Jersey: Princeton University Press.

Tindale, N. B. 1935a AA338/1/14: Anthropological Expedition to Warburton Range, WA by Norman B. Tindale, July-Sept 1935, Journal. Norman Tindale Collection, Adelaide: South Australian Museum.

Tindale, N. B. 1935b AA 338/5/14: Photographs relating to the Anthropological Expedition to Warburton Range, Western Australia, 1935. Norman Tindale Collection, Adelaide: South Australian Museum.

Tindale, N. B. 1936 General report on the anthropological expedition to the Warburton Range. Western Australia, July-September 1935, Oceania 6(4): 481-5.

Tindale, N. B. 1951 AA338/2/39: Tindale Yuendumu Journal, 1951. Norman Tindale Collection, Adelaide: South Australian Museum.

Tindale, N. B. 1963 AA338/11/23/3: Ray a Ngadadjara man tells the story of his first encounter with white men, Rawlinson Range Expedition (WA) 1963. Audio recording. In Norman Tindale Collection. Adelaide: South Australian Museum.

Tindale, N. B. 1974 Aboriginal Tribes of Australia: Their Terrain, Environmental Controls, Distribution, Limits, and Proper Names. Berkeley: University of California Press.

Tindale, N. B. and B. George 1971 The Australian Aborigines. Potts Point, New South Wales: Golden Press.

Tonkinson, R. 1991 The Mardu Aborigines: Living the Dream in Australia's Desert, 2nd edn. Sydney: Holt, Rinehart and Winston Inc. 